\title{
Проблемы отечественного оперативно-розыскного законодательства и преАмжения по их разрешению с учетом опыта некоторых стран СНГ
}

\author{
А. В. АГАРКОВ \\ Владимирский юридический институт ФСИН России, г. Владимир, Россий- \\ ская Федерация \\ ORCID: https://orcid.org/0000-0001-5326-9757, e-mail: oper72.kum@mail.ru
}

\section{Р е фер а т}

Введение: как показывают правоприменительная практика и научные исследования в области теории оперативно-розыскной деятельности, в современном оперативно-розыскном законодательстве России существует значительное количество правовых пробелов и противоречий. В статье осуществлен научный анализ ряда проблемных вопросов нормативного правового регулирования оперативно-розыскной деятельности, осуществляемой в Российской Федерации, причем акцент сделан на функционировании оперативных подразделений уголовно-исполнительной системы Российской Федерации. Цель: на основе обобщения оперативно-розыскного законодательства стран СНГ, анализа работ ряда ученых, разрабатывающих проблемы теории оперативно-розыскной деятельности, нормативной правовой базы деятельности оперативных подразделений выработать предложения по совершенствованию отечественного оперативно-розыскного законодательства. Методы: сравнительно-правовой, теоретические методы формальной и диалектической логики, частнонаучные методы: юридико-догматический и метод толкования правовых норм. Результаты: в качестве основных проблем в статье рассматриваются несоответствие закрепленной в законе цели оперативно-розыскной деятельности как правоприменительной практике, так и законодательно определенным ее задачам, отсутствие ряда значимых задач, а также оснований для проведения оперативно-розыскных мероприятий оперативными подразделениями уголовно-исполнительной системы, отсутствие правовой регламентации содержания и порядка осуществления оперативно-розыскных мероприятий. В качестве иллюстрации имеющихся недостатков научному анализу подвергнуты наиболее распространенные оперативно-розыскные мероприятия - опрос и наведение справок. В результате изучения оперативно-розыскных законов ряда государств, входящих в СНГ, обнаружены регламентирующие оперативно-розыскную деятельность в пенитенциарной системе нормы, использование которых, по нашему мнению, возможно в отечественных реалиях. Исходя из этого, вносятся предложения по совершенствованию правового регулирования оперативно-розыскной деятельности, в частности, путем раскрытия понятия каждого оперативно-розыскного мероприятия в нормах оперативно-розыскного закона. Выводы: в статье разработаны и обоснованы предложения по совершенствованию отечественного оперативно-розыскного закона и делается вывод о необходимости коренного преобразования законодательного регулирования оперативно-розыскной деятельности в России путем принятия соответствующего кодекса.

Ключевые слова: оперативно-розыскная деятельность; оперативно-розыскные мероприятия; недостатки; проблемы; оперативно-розыскной закон; теория оперативно-розыскной деятельности; оперативно-разыскной кодекс.

12.00.12 - Криминалистика; судебно-экспертная деятельность; оперативно-розыскная деятельность (юридические науки).

Для цитирования: Агарков А. В. Проблемы отечественного оперативно-розыскного законодательства и предложения по их разрешению с учетом опыта некоторых стран СНГ. Пенитенциарная наука, 2021, т. 15, № 1 (53), с. 85-95. DOI 10.46741/2686-9764-2021-15-1-85-95. 


\title{
Russian Law Enforcement Intelligence-Gathering Legislation: Problems and Ways to Address Them, Taking into Account the Experience of Some CIS Countries
}

\author{
ALEKSEI V. AGARKOV \\ Vladimir Law Institute of the Federal Penitentiary Service of Russia, Vladimir, \\ Russian Federation \\ ORCID: https://orcid.org/0000-0001-5326-9757, e-mail: oper72.kum@mail.ru
}

\begin{abstract}
A b s t r a c t. Introduction: law enforcement practice and scientific research in the field of the theory of intelligence-gathering activities prove that current Russian intelligencegathering legislation contains quite a few legal gaps and contradictions. The article provides a scientific analysis of a number of problematic issues concerning legal regulation of intelligence-gathering activities conducted in the Russian Federation, with an emphasis on the functioning of operational units of the penal system of the Russian Federation. Aim:to work out proposals to improve national intelligence-gathering legislation by reviewingintelligence-gathering legislation of CIS countries, analyzing the works of scientists on the theory of intelligence-gathering activities and regulatory framework for the work of operational units. Methods: comparative legal method, theoretical methods of formal and dialectical logic, specific scientific methods: legal-dogmatic method, interpretation of legal norms. Results: the article considers the inconsistency between the purpose of intelligence-gathering activities enacted in law and both the law enforcement practice and its legally defined tasks, the absence of a number of significant tasks, as well as the grounds for conducting intelligence-gathering activities by operational units of the penal system, the lack of legal regulation of the content of intelligence-gathering activities and their procedure. To prove the existence of these shortcomings, we analyze the most common intelligence-gathering measures such as questioning and inquiries. Having studied intelligence-gathering laws of several CIS countries we found some norms regulating intelligence-gathering activities in the penitentiary system, the use of which, in our opinion, is possible in Russian context. Based on this, we make proposals to improve legal regulation of intelligence-gathering activities, in particular, by disclosing the concept of each intelligence-gathering activity in the norms of intelligence-gathering law. Conclusions: the article develops and substantiates proposals for improving Russia'sintelligence-gathering law and concludes that it is necessary to transform fundamentally the legislative regulation of intelligence-gathering activities in Russia by adopting the appropriate code.

Keywords: intelligence-gathering activities; intelligence-gathering measures; shortcomings; problems; intelligence-gathering law; theory of intelligence-gathering activities; intelligence-gathering code.
\end{abstract}

12.00.12 - Criminalistics; forensic activities; intelligence-gathering activities.

For citation: Agarkov A.V. Russian law enforcement intelligence-gathering legislation: problems and ways to address them, taking into account the experience of some CIS countries. Penitentiary Science, 2021, vol. 15, no. 1 (53), pp. 85-95. DOI 10.46741/2686-9764-2021-15-1-85-95.

\section{Введение}

В научных публикациях неоднократно отмечалось, что существующее оперативно-розыскное законодательство несовершенно, в том числе в части регулирования основы оперативно-розыскной деятельности (ОРД) - осуществления оперативнорозыскных мероприятий (ОРМ) [1; 2; 3; 17]. Учеными постоянно предлагались и предлагаются пути улучшения оперативно-розыскного закона, однако поддержки законодателя данные разработки, к сожалению, не находят. В 2015 г. была предпринята попытка кардинально разрешить существующую ситуацию путем принятия нового федерального закона - оперативно-разыскного кодекса [7], однако в связи с несовершенством представленного проекта эта инициатива была отвергнута на этапе согласования с заинтересованными министерствами и ведомствами - субъектами оперативнорозыскной деятельности.

Исходя из сказанного выше, мы считаем целесообразным предпринять попытку 
краткого анализа основных проблем оперативно-розыскного законодательства, рассматривая их в том числе применительно к деятельности оперативных подразделений уголовно-исполнительной системы Российской Федерации (далее - УИС). Прежде всего необходимо обозначить терминологическую проблему, существование которой может повлиять на результаты юридической оценки судом результатов оперативно-розыскной деятельности. Речь идет о правописании. К сожалению, даже в этом аспекте имеются сложности, способные вызвать юридические последствия. Как известно, Федеральный закон от 12.08.1995 № 144-Ф3 «Об оперативно-розыскной деятельности» (далее - Ф3 «Об ОРД») содержит фундаментальное понятие «оперативно-розыскная деятельность» в написании через букву «0». Указанный вариант написания является традиционным и используется во всей научной и учебной литературе по ОРД, изданной до начала XXI в. Вместе с тем в 2006 г. главный редактор журнала «Оперативник (сыщик)» профессор А. Ю. Шумилов, отвечая на вопросы читателей, опубликовал пояснение справочной службы русского языка, гласящее, что написание «разыскной» получило закрепление в качестве нормативного в «Русском орфографическом словаре» 1999 г., а также «Большом толковом словаре русского языка» 2001 г. Следует писать «разыскной», «разыскник», «оперативно-разыскной» и т. д. Эта публикация послужила отправной точкой для широкой дискуссии среди юристов, разделившихся на сторонников традиционного и нового вариантов. Проблема осложнилась тем, что законодатель, не изменив написания в ФЗ «Об ОРД», стал в других законах использовать новый вариант. Так, ст. 12 Федерального закона от 07.02.2011 № 3-Ф3 «О полиции» предусматривает обязанность полиции «осуществлять оперативно-разыскную деятельность», в 2014 г. ст. 65 Федерального закона от 02.10.2007 № 229Ф3 «Об исполнительном производстве» была дополнена ч. 1.1, в содержании которой использовался термин «исполнительно-разыскные действия». Нам видится необходимым пояснить свою позицию относительно правильности написания этого слова: опираясь на мнения специалистов в области как русского языка [10], так и юриспруденции [19], мы считаем предпочтительным написание «оперативно-разыскной», однако использовать его представляется возможным лишь после внесения соответствующих изменений в ФЗ «Об ОРД».

Проблемные вопросы современного законодательного регулирования целей и задач оперативно-розыскной деятельности

Основным постулатом современной оперативно-розыскной деятельности является закрепленная в ст. 1 ФЗ «Об ОРД» ее цель защита человека и гражданина, общества и государства от преступных посягательств. Анализируя иные нормы ФЗ «Об ОРД», а также актуальную практику деятельности оперативных подразделений, приходится констатировать, что современная цель ОРД намного шире указанной. Так, внимательное изучение ст. 2 ФЗ «Об ОРД» «Задачи оперативно-розыскной деятельности» дает нам кроме задач, имеющих отношение к борьбе с преступностью, розыск без вести пропавших, добывание информации о событиях или действиях (бездействии), создающих угрозу безопасности Российской Федерации, установление имущества, подлежащего конфискации. Подчеркнем, что мы нисколько не сомневаемся в важности и значимости перечисленных задач, однако не можем не указать на выявленное нами несоответствие.

При этом, рассматривая законодательное регулирование задач современной оперативно-розыскной деятельности в Российской Федерации, нельзя не отметить, что их перечень, предусмотренный ст. 2 ФЗ «Об ОРД», не только не отражает фактически сложившуюся и одобряемую решениями судов правоприменительную практику, но и противоречит ряду статей непосредственно ФЗ «Об ОРД», а также иных действующих федеральных законов. Представляется целесообразным еще раз обратить внимание читателя на то, что указанный перечень лапидарен и включает задачи, направленные на противодействие преступности, розыск различных категорий лиц (среди которых, однако, нет осужденных), добывание информации о событиях или действиях (бездействии), создающих угрозу безопасности России, а также нехарактерную для большинства правоохранительных органов задачу установления подлежащего конфискации имущества.

Обосновывая приведенные выше тезисы, следует затронуть следующие аспекты. Вопервых, основания проведения оперативно-розыскных мероприятий, приведенные в 
ст. 7 ФЗ «Об ОРД», намного шире указанных задач и включают в себя основания, как действительно связанные с перечисленными задачами, так и выходящие за их пределы. Так, по нашему мнению, не соответствуют ст. 2 ФЗ «Об ОРД» основания, предусмотренные ч. 2 и 3 ст. 7 ФЗ «Об ОРД». Речь в них идет об оперативно-проверочной работе, заключающейся в сборе сведений о благонадежности различных категорий лиц, а также проверке сведений, представленных гражданами, замещающими либо претендующими на замещение ряда должностей государственной, муниципальной и иной службы.

Еще одним проблемным, на наш взгляд, моментом является противоречие между ФЗ «Об ОРД» и ст. 84 УИК РФ, устанавливающей задачи оперативно-розыскной деятельности в исправительных учреждениях. Значимые отличия от ФЗ «Об ОРД», как представляется, содержат задачи обеспечения личной безопасности различных категорий лиц, противодействие совершению нарушений режима содержания, розыск совершивших побег осужденных. При этом особо следует подчеркнуть, что нарушения установленного порядка отбывания наказания преступлениями не являются, следовательно, задача борьбы с ними ст. 1, 2, 7 ФЗ «Об ОРД» не предусмотрена, что делает невозможным проведение оперативно-розыскных мероприятий для ее решения. Таким образом, существует ситуация, в которой есть «мишень» (нарушения установленного порядка отбывания наказания), есть необходимость «стрельбы» (ст. 84 УИК РФ), есть «оружие» (ОРД), но нет «патронов» (оснований для проведения ОРМ).

Мнение о необходимости устранения данного недостатка сформировалось у ряда ученых, разрабатывающих оперативно-розыскную проблематику. Указанная проблема не нова: еще в 1994 г. об этом писали Н. Н. Васильев и А. Ф. Кваша, предлагая дополнить ст. 7 ФЗ «Об ОРД» частью, устанавливающей такое основание для проведения оперативно-розыскных мероприятий, как необходимость добывания информации, использование которой обеспечивает правопорядок и законность в пенитенциарных учреждениях [6]; в 2006 г. на ней акцентировал внимание профессор К. К. Горяинов [4]; в 2012 г. профессор В. М. Атмажитов указывал, что «борьба с преступностью действительно является важнейшей, но не единственной составляющей цели такой деятельности. В процессе ее осуществления нередко решаются также задачи, выходящие за рамки непосредственно борьбы с преступностью. К таким задачам, в частности, относятся... поддержание в исправительных учреждениях режима, установленного уголовно-исполнительным законодательством...» [2]. Однако за прошедшие годы положение не изменилось. Таким образом, следует констатировать, что в настоящее время в отношении правовой базы деятельности оперативных подразделений УИС сложилась ситуация, когда существует задача, но отсутствует зафиксированный в законодательстве механизм ее решения.

Более того, аналогичная проблема возникает при реализации положений ст. 18.1 УИК РФ, предусматривающей, что ОРД при исполнении наказаний, не связанных с отбыванием лишения свободы, осуществляется оперативными подразделениями уголовно-исполнительной системы Российской Федерации самостоятельно или во взаимодействии с иными субъектами ОРД, а розыск лиц, уклоняющихся от таких наказаний, производится оперативными подразделениями УИС. Исходя из отсутствия иных норм, очевидно, что ОРД в отношении данной категории осужденных возможно осуществлять, в соответствии с ФЗ «Об ОРД», лишь для решения задачи выявления, предупреждения, пресечения и раскрытия преступлений, причем уклонение осужденного от отбывания основного наказания, не предусматривающего лишения свободы, преступлением не является. Исключение, в соответствии со ст. 314 Уголовного кодекса Российской Федерации, составляет лишь злостное уклонение от отбывания наказания в виде ограничения свободы.

Исследуя пути решения обозначенной проблемы, мы обратились к оперативнорозыскному законодательству ряда государств стран СНГ, так как после распада СССР составлявшие его республики пошли каждая по своему пути, в том числе и в области законодательного регулирования ОРД, наработав при этом заслуживающий внимания опыт.

Рассматривая нормы Закона Республики Казахстан от 15.09.1994 № 154-XIII «Об оперативно-розыскной деятельности», можно обнаружить, что задачи ОРД в этом государстве значительно шире тех, что предусмотрены российским оперативно-розыск- 
ным законом, и направлены они не только на борьбу с преступностью. Так, одной из них выступает обеспечение установленного режима и безопасности лиц в пенитенциарных учреждениях. Кроме того, положительным моментом, выгодно отличающим казахстанское оперативно-розыскное законодательство, нам представляется отражение в нем таких задач, аналогичные которым в России либо закреплены в иных, кроме ФЗ «Об ОРД», законах (например, обеспечение безопасности охраняемых лиц), либо не урегулированы вообще (обеспечение защиты государственной или иной охраняемой законом тайны, в том числе коммерческой, и др.) [9].

Интересны задачи, определенные оперативно-розыскным законодательством Республики Беларусь. Они, в отличие от аналогичных российских норм, предусматривают следующие актуальные и для нашей страны позиции: розыск осужденных, идентификацию неопознанных трупов, установление персональных данных граждан, которые не могут сообщить сведения о себе, обеспечение безопасности конфидентов, их близких, иных граждан в соответствии с законодательством, упоминавшуюся нами выше оперативно-проверочную работу, а также защиту государственных секретов [8]. Вышеизложенное показывает, что белорусский закон предусматривает задачи, во многом соотносящиеся с содержащимися в Ф3 «Об ОРД» основаниями для проведения ОРМ, однако не входящие в перечень задач, решаемых ОРД в России. Вместе с тем белорусским законодателем не закреплено в качестве задачи ОРД обеспечение установленного порядка режима содержания в местах лишения свободы.

Предпринятый нами анализ оперативнорозыскного законодательства Азербайджанской Республики, Республики Кыргызстан, Республики Молдова, Республики Таджикистан показал, что установленные соответствующими законами перечни задач ОРД несколько шире отечественных: в большинстве случаев они включают розыск пропавших без вести граждан, а также обеспечение охраны государственной границы, противодействие разведывательно-подрывной деятельности специальных служб иностранных государств и др. Вместе с тем задача обеспечения установленного режима в местах лишения свободы в оперативно-розыскном законодательстве упомянутых государств отражения не получила (исключение составляет закон «Об ОРД» Республики Армении, декларирующий в качестве цели ОРД защиту от противоправных (курсив наш. - А. А.) посягательств, а также предусматривающий среди задач¹ ОРД «обеспечение нормальной деятельности уголовно-исполнительных учреждений»).

Пробелы правовой регламентации осуществления оперативно-розыскных мероприятий

Продолжая анализ норм существующего оперативно-розыскного закона, нельзя не остановиться на нормах ст. 6 ФЗ «Об ОРД» «Оперативно-розыскные мероприятия». Часть 1 содержит исчерпывающий перечень OPM, разрешенных для проведения в Российской Федерации, однако не включает ни понятия оперативно-розыскного мероприятия, ни расшифровки содержания перечисленных ОРМ. Результатом этого становится возможность произвольно толковать нормы Ф3 «Об ОРД» в части понимания способов осуществления ОРД, так как в соответствии со ст. 1 ФЗ «Об ОРД» ОРД осуществляется посредством проведения ОРМ. Как отмечают И. Д. Шатохин и А. Е. Чечетин, одной из распространенных проблем, поднимаемых в жалобах граждан в Конституционный Суд Российской Федерации, является неопределенность норм, регламентирующих проведение ОРМ, прежде всего ст. 6 Ф3 «Об ОРД» [15, с. 64].

Вновь возвращаясь к оперативно-розыскному законодательству стран СНГ, заметим, что законы Казахстана и Таджикистана раскрывают содержание каждого ОРМ в ст. 1, где приводятся определения основных понятий (заметим, кстати, что, по нашему мнению, аналогичная статья была бы весьма востребована и в отечественном оперативно-розыскном законе). В законе «Об оперативно-розыскной деятельности» Кыргызской Республики основные понятия, включая содержание ОРМ, даются в ст. 2. Законы «Об оперативно-розыскной деятельности» Республики Армении и Республики Беларуси раскрывают содержание OPM в соответствующих нормах, рассматривающих ОРМ.

\footnotetext{
${ }^{1}$ Статья 4 закона «Об ОРД» Республики Армении носит название «Цели оперативно-розыскной деятельности», однако, исходя из того, что цель уже сформулирована в ст. 3 указанного закона, а также из того, что ст. 4 включает в себя 16 пунктов, и учитывая возможность недостаточно точного перевода, мы сочли допустимым использовать (по аналогии с отечественным оперативно-розыскным законом) более точное понятие - задачи.
} 
Проблема отсутствия законодательных определений ОРМ неоднократно поднималась в научной печати [13; 20], однако, несмотря на это, законодатель ее игнорирует. Заметим, что полное отсутствие регламентации проведения ОРМ влечет за собой вопросы, ответы на которые дает исключительно правоприменительная и судебная практика, что не может являться допустимым в столь значимой сфере, связанной в числе прочего с ограничением прав и свобод человека и гражданина.

При исследовании ОРМ «опрос», названного первым в ч. 1 ст. 6 ФЗ «Об ОРД», возникают следующие вопросы: возможно ли проведение опроса без согласия опрашиваемого лица? необходимо ли разъяснять опрашиваемому лицу содержание ст. 51 Конституции Российской Федерации? следует ли обеспечивать участие адвоката (защитника), если на его участии настаивает опрашиваемый? возможно ли использование результатов опроса в качестве доказательства в уголовном судопроизводстве? Кроме того, следует напомнить, что ОРД, согласно ст. 1 ФЗ «Об ОРД», может осуществляться гласно и негласно, а потому дополним приведенный перечень вопросов: возможно ли проведение опроса опосредованно? Эта проблема не надумана, а имеет прямое практическое значение, так как в современном мире возможны и видеосвязь, и обмен текстовыми и графическими сообщениями с помощью специальных компьютерных программ (Skype, Zoom, Viber, WhatsApp и др.). Соответственно: является ли опросом обмен текстовыми сообщениями в режиме реального времени? с паузами между репликами до нескольких часов? имеет ли право один из собеседников предоставить материалы такого опроса в качестве доказательства, не имея судебного решения на проведение опроса?

Еще раз подчеркнем, что, отвечая на указанные вопросы, мы лишь выразим авторскую точку зрения, тогда как, по нашему мнению, исчерпывающие заключения по данной проблеме должны содержаться в оперативно-розыскном законодательстве. Итак, мы считаем, что проведение гласного опроса возможно лишь с согласия опрашиваемого, выраженного устно или письменно. При этом ст. 51 Конституции Российской Федерации должна быть разъяснена опрашиваемому, но только в том случае, если опрос проводится без зашифровки цели и оформляется письменным объяснением лица либо фиксируется с помощью видео-, аудиотехники. Только при соблюдении указанных условий, по нашему мнению, материалы опроса могут быть впоследствии использованы в уголовном судопроизводстве. Если при этом опрашиваемый настаивает на участии в опросе адвоката (защитника), то это участие следует обеспечить, также как и в случаях, не предполагающих введения результатов опроса в уголовный процесс (исключительно при инициативе опрашиваемого лица). Отвечая на следующий вопрос, следует повториться, что в связи с развитием коммуникационных технологий в настоящее время представляется неприемлемым сводить опрос лишь к беседе (и тем более непосредственной беседе), исходя из понимания беседы как межличностного речевого общения. В этом случае остаются вне поля, очерчиваемого многими существующими в научной литературе определениями опроса, такие формы общения, как диалоги, ведущиеся с помощью социальных сетей, электронной почты, sms-сообщений, специализированных компьютерных программ, обеспечивающих зрительное, слуховое общение собеседников, находящихся вне пределов прямой видимости друг друга, а также поддерживающих возможность письменного общения пользователей. Что же касается использования материалов опосредованного опроса в качестве доказательства, то следует признать, что в случае отсутствия письменного согласия опрошенного лица в настоящее время необходимо получать судебное решение на его проведение (как бы непривычно это ни звучало для правоприменителей). Проблема заключается в том, что в соответствии с решением Конституционного Суда Российской Федерации «информацией, составляющей... тайну телефонных переговоров, считаются любые сведения, передаваемые, сохраняемые и устанавливаемые с помощью телефонной аппаратуры» [11]. Учитывая, что подавляющее большинство так называемых мессенджеров используется на устройствах, с помощью которых ведутся телефонные переговоры, мы приходим к выводу, что содержание такого опроса составляет тайну телефонных переговоров. При этом следует подчеркнуть, что возможность использования в качестве доказательства результатов опроса, в том числе опосредованного и проведенного 
оперативным сотрудником без расшифровки принадлежности к оперативным подразделениям, необходимо закрепить в оперативно-розыскном законе.

Не меньшее количество вопросов возникает при анализе содержания следующего по порядку ФЗ «Об ОРД» ОРМ - наведения справок. Главные из них: как понимать содержание данного мероприятия? где закреплена обязанность должностных лиц и граждан отвечать на запросы субъектов ОРД? требуется ли судебная санкция на запрос сведений в банковских организациях, учреждениях здравоохранения, у нотариусов, в налоговых органах, изучение сведений, содержащихся в страницах социальных сетей, доступ к которым ограничен (и является ли это составом рассматриваемого ОРМ)?

Предпримем попытку ответить на эти вопросы. Итак, по нашему мнению, наведение справок - изучение оперативной информации, получаемой тремя путями, два из которых могут считаться классическими в связи с их постоянным упоминанием в научной литературе: изучение носителей информации, к которым имеется постоянный или временный доступ, и направление запросов гражданам и организациям. Следует особо отметить, что именно эта форма получила косвенное закрепление в ст. 12.1 ФЗ «Об ОРД», содержание которой будет рассмотрено ниже. Вместе с тем хотелось бы еще раз подчеркнуть, что наше время - время постоянного технического прогресса, за которым не всегда успевают отечественное законодательство и ведомственные акты. Исходя из сказанного, мы считаем необходимым выделить еще одну форму проведения рассматриваемого ОРМ - использование поисковых запросов в различных электронных информационных сетях, в первую очередь в сети Интернет. «Всемирная паутина» является хранилищем гигантского количества информации, получение доступа к которой - вопрос умения и техники. Вместе с тем, по нашему мнению, осуществление посредством технических и программных средств доступа к закрытой для всех пользователей странице социальной сети образует состав уже иного ОРМ получения компьютерной информации, для проведения которого требуется судебное санкционирование.

Продолжая анализ правовых проблем ОРМ «наведение справок», мы должны указать на существующую правовую коллизию.
С одной стороны, в ст. 8 ФЗ «Об ОРД» «УСловия проведения оперативно-розыскных мероприятий» приведен исчерпывающий список прав граждан, которые могут быть ограничены в ходе ОРД: тайна переписки, телефонных переговоров, почтовых, телеграфных и иных сообщений, право на неприкосновенность жилища. Однако ч. 5 ст. 26 «Банковская тайна» Федерального закона от 02.12.1990 № 395-1 «О банках и банковской деятельности» содержит предписание о том, что «справки по операциям и счетам юридических лиц и индивидуальных предпринимателей, по операциям, счетам и вкладам физических лиц выдаются на основании судебного решения (курсив наш. - А. А.) кредитной организацией должностным лицам органов, уполномоченных осуществлять оперативно-разыскную деятельность ${ }^{1}$, при выполнении ими функций по выявлению, предупреждению и пресечению преступлений». Из анализа данной нормы следует, что указанные сведения могут быть предоставлены лишь при решении одной из четырех задач, предусмотренных ст. 2 ФЗ «Об ОРД», и не предоставляются при решении иных задач, например рассмотренной нами выше задачи оперативных подразделений УИС по противодействию совершению нарушений режима содержания. Разрешение существующей коллизии, по нашему мнению, возможно лишь путем изменения норм оперативно-розыскного закона. Что же касается правового режима доступа к иным сведениям закрытого характера, составляющим врачебную, налоговую, нотариальную и иные виды тайн, предусмотренных отечественным законодательством, то его отсутствие свидетельствует о существовании правового пробела, устранимого лишь путем внесения дополнений в оперативнорозыскной закон. При этом на сегодняшний день оперативные подразделения в основном имеют доступ к указанным сведениям, который обеспечивается в зависимости от практики, сложившейся в конкретном регионе.

Необходимо выделить еще один значимый, по нашему мнению, аспект: отечественное законодательство не содержит санкций за нарушение норм ФЗ «Об ОРД». Преступившие его должностные лица привлекаются к дисциплинарной или уголовной ответственности (если в их действиях

\footnotetext{
${ }^{1}$ Еще один пример второго варианта написания термина «розыскной».
} 
содержится самостоятельный состав преступления), тогда как граждане в такой же ситуации к существующим видам ответственности привлечены быть не могут, что говорит об исключительной добровольности действий последних в сфере оперативно-розыскных правоотношений. В этой связи несколько необоснованным с правовой точки зрения представляется внесенный законодателем 30.12.2020 запрет на разглашение сведений об осуществлении оперативно-розыскной деятельности (ст. 12.1 Ф3 «Об ОРД»): «Сведения, содержащиеся в запросах, направляемых гражданам и организациям в процессе осуществления оперативно-розыскной деятельности, не подлежат разглашению»1. Более того, в связи с отсутствием определения ОРМ «наведение справок» (и, возможно, по воле законодателя) отсутствует обязанность граждан и организаций отвечать на поступившие им от оперативных подразделений запросы.

К сожалению, при рассмотрении каждого ОРМ возможно выделить массу подобных правовых проблем, в связи с чем, продемонстрировав это на двух примерах, мы считаем необходимым обратить внимание читателя еще на один значимый с точки зрения обеспечения прав и свобод человека и гражданина аспект - принуждение при проведении ОРМ. Как и некоторые другие перечисленные нами выше, этот вопрос неоднократно поднимался различными учеными [5; 12, с. 62; 14; 18, с. 106], однако не нашел своего законодательного закрепления. Суть проблемы заключается в следующем: ряд правоприменителей, руководствуясь положением ст. 1 ФЗ «Об ОРД» о том, что ОРД может осуществляться гласно и негласно, организуют гласное проведение ОРМ (разумеется, без согласия лиц, в отношении которых проводятся ОРМ). В этом в ряде случаев участвуют некие представители общественности, выполняющие функцию не предусмотренных Ф3 «Об ОРД» понятых. Норма ч. 2 ст. 15 ФЗ «Об ОРД» регламентирует порядок оформления изымаемых при проведении гласных ОРМ документов, предметов, материалов, что позволило не только правоприменителям, но и части ученых [16] прийти к выводу о законности указанных действий. В результате происходит подмена предусмотренных уголовно-процессуальным законом следственных действий неким суррогатом,

\footnotetext{
${ }^{1}$ При условии отсутствия в них сведений, составляющих государственную тайну.
}

не отвечающим требованиям законности. Вместе с тем приходится констатировать, что суд не только не запрещает указанную деятельность, но и принимает полученные таким образом сведения в качестве доказательств. Мы категорически отвергаем подобную практику, соглашаясь с однозначно выраженной позицией профессоров А. Е. Чечетина [14] и В. К. Зникина [5]: гласные ОРМ не могут и не должны подменять собой следственные действия.

Вместе с тем могут иметь место случаи, при которых проведение гласных ОРМ, в том числе с изъятием чего-либо, необходимо. По нашему мнению, это возможно в двух вариантах: при наличии недвусмысленно выраженного согласия лица или при получении судебного разрешения. В обеих ситуациях для обеспечения законности необходимо участие лиц, которые впоследствии могут дать показания в суде о том, что они видели и слышали в ходе ОРМ. Как уже отмечалось, действующий оперативно-розыскной закон не предусматривает такого участия, поэтому правоприменители именуют данных лиц по-разному: присутствующие лица, представители общественности и др. Полагаем, необходимо законодательно определить их статус и функции при проведении гласных OPM.

\section{Заключение}

Резюмируя все вышесказанное, мы считаем необходимым отметить следующее.

Нами, в том числе на основе анализа работ иных ученых, были выделены лишь некоторые проблемы современного оперативнорозыскного закона. Очевидно, что устранить их путем внесения разовых изменений в действующий ФЗ «Об ОРД» невозможно, требуется комплексный научный подход к разработке и принятию нового закона, который бы регламентировал многочисленные аспекты оперативно-розыскной деятельности, не вторгаясь при этом в ее тактику. Здесь необходимо соблюсти баланс интересов, с одной стороны, обеспечивая в правоприменительной практике заявленные в Конституции Российской Федерации и ФЗ «Об ОРД» принципы законности и уважения прав и свобод человека и гражданина, с другой - не лишая оперативные подразделения возможности как использовать оперативнорозыскные силы, средства и методы, так и законным путем добывать доказательства для последующего использования в уголовном судопроизводстве. 
Представляется, что сделать это возможно лишь путем разработки и принятия нового закона - оперативно-разыскного кодекса. Такая попытка уже предпринималась профессором В. Ф. Луговиком [7]. Разработанный им проект указанного кодекса был внесен в Государственную Думу Российской Федерации, однако не нашел поддержки со стороны министерств и ведомств, уполномоченных на осуществление ОРД.

В результате субъективного анализа современного состояния совершенствования оперативно-розыскного законодательства нам видится возможным обозначить следующую негативную тенденцию: учеными, в том числе имеющими значительный научный опыт и авторитет, выявляются, обосновываются с учетом существующей правоприменительной практики и отражаются в научной литературе значимые проблемы законодательного регулирования ОРД, ими же в ходе научной дискуссии вырабатываются значимые пути разрешения выявленных проблем, которые также становятся предметом публикаций в профильных изданиях, однако законодателем указанные работы игнорируются, а вносимые им изменения, как и стратегия разработки оперативно-розыскного закона, носят точечный характер, причем закрытый от научной общественности. Таким образом, налицо разрыв науки с законодательной практикой, невостребо- ванность имеющихся научных разработок, что в существующих условиях представляется недопустимым.

\section{Выводы}

Исходя из всего вышесказанного, используя как опыт оперативно-розыскного законодательства стран СНГ, так и опубликованные ранее различными учеными научные работы, мы считаем возможным утверждать, что назрела необходимость значительного совершенствования российского оперативно-розыскного закона, в первую очередь в части регламентации оперативнорозыскных мероприятий. Представляется, что основными направлениями этой работы должны стать: учет практики осуществления оперативно-розыскной деятельности, результатов прокурорских проверок ее законности, позиции судов при рассмотрении дел с использованием результатов оперативно-розыскной деятельности, современные научные разработки в области законодательной регламентации ОРД, учитывающие зарубежный опыт.

Заметим, что мы ни в коей мере не претендуем на безапелляционность рассуждений. Вместе с тем, вновь привлекая внимание к поднятым в настоящей публикации проблемам, надеемся на возможность внесения давно назревших изменений в отечественный оперативно-розыскной закон.

\section{СПИСОК ЛИТЕРАТУРЫ}

1. Атмажитов, В. М. О законодательном регулировании оперативно-розыскной деятельности : научный доклад / В. М. Атмажитов, В. Г. Бобров. - Москва : ИД Шумилова И. И., 2003. - 23 с. - ISBN 5-89784-069-5.

2. Атмажитов, В. М. О сущности и правовой основе оперативно-розыскной деятельности : научный доклад / В. М. Атмажитов // Конституционно-правовые проблемы оперативно-розыскной деятельности : сборник материалов Всероссийского круглого стола (3 ноября 2011 г.) / составитель К. Б. Калиновский. - Москва : Петрополис, 2012. - С. 69-86. - ISBN 978-5-9676-0434-8.

3. Бобров, В. Г. О некоторых вопросах законодательного регулирования оперативно-розыскной деятельности / В. Г. Бобров // Полицейское право.- 2005. - № 2. - С. 75-83.

4. Горяинов, К. К. Некоторые направления развития оперативно-розыскной деятельности в уголовно-исполнительной системе / К. К. Горяинов // Оперативник (сыщик). - 2006. - № 1 (6). - С. 17-20.

5. Зникин, В. К. Гласное оперативно-розыскное мероприятие не может быть следственным действием / В. К. Зникин // Вестник Кузбасского института. - 2019. - № 4 (41). - С. 142-146.

6. Кваша, Ю. Ф. Основные направления (концепция) оперативно-розыскной деятельности оперативных подразделений органов и учреждений, исполняющих уголовные наказания : учебно-методические материалы по курсу «Организация и тактика ОРД органов, исполняющих наказания» / Ю. Ф. Кваша, Н. Н. Васильев. - Москва : Академия МВД России, 1994. - С. 22-23.

7. Луговик, В. Ф. Оперативно-разыскной кодекс Российской Федерации (авторский проект федерального закона) // Юридическая наука и правоохранительная практика. - 2015. - № 1 (31). - C. 109-135. - URL: https://cyberleninka. ru/article/n/operativno-razysknoy-kodeks-rossiyskoy-federatsii-avtorskiy-proekt-federalnogo-zakona/viewer (дата обращения: 06.01.2021).

8. Об оперативно-розыскной деятельности : закон Республики Беларусь // Национальный центр правовой информации Республики Беларусь «Эталон» : официальный сайт. - URL: https://etalonline.by/document/?regnum=H11500307 (дата обращения: 24.01.2021).

9. Об оперативно-розыскной деятельности : закон Республики Казахстан от 15.09.1994 № 154-XIII // Информационно-правовая система нормативных правовых актов Республики Казахстан : официальный сайт. - URL: http:// adilet.zan.kz/rus/docs/Z940004000_/links (дата обращения: 24.01.2021).

10. Оганесян, С. С. Как правильно писать «разыскной» или «розыскной»? / С. С. Оганесян // Актуальные вопросы совершенствования российского законодательства и деятельности уголовно-исполнительной си- 
стемы : сборник научных трудов / под редакцией Е. С. Ткаченко. - Владимир : ВЮИ ФСИН России, 2019. C. $286-291$.

11. Определение Конституционного Суда Российской Федерации от 2 октября 2003 г. № 345-О «Об отказе в принятии к рассмотрению запроса Советского районного суда города Липецка о проверке конституционности части четвертой статьи 32 Федерального закона от 16 февраля 1995 года «О связи»» // Оперативно-розыскные мероприятия: основания и условия их проведения : сборник решений Европейского Суда по правам человека, Конституционного и Верховного Судов Российской Федерации / составители К. К. Горяинов, Л. Е. Щетнёв. - Владимир : ВЮИ ФСИН России, 2017. - С. 48-50. - ISBN 978-5-93035-643-4.

12. Федеральный закон «Об оперативно-розыскной деятельности» : научно-практический комментарий / В. В. Николюк [и др.]. - Омск : Омский юридический институт МВД России, 1999. - 179 с. - ISBN 5-7998-0007-9.

13. Чечетин, А. Е. Актуальные проблемы теории оперативно-розыскных мероприятий : монография / А. Е. Чечетин. - Москва : ИД Шумиловой И. И., 2006. - 180с. - ISBN5-89784-101-2.

14. Чечетин, А. Е. Современная оперативно-розыскная деятельность и принуждение / А. Е. Чечетин // Оперативник (сыщик). - 2015. - № 1 (42). - С. 37-42.

15. Шатохин, И. Д. Принцип уважения и соблюдения прав и свобод человека и гражданина в оперативно-розыскной деятельности : монография / И. Д. Шатохин, А. Е. Чечетин. - Барнаул : Барнаульский юридический институт МВД России, 2020. - 206 с. - ISBN 978-5-94552-408-8.

16. Шашин, Д. Г. Гласное обследование помещений, зданий, сооружений, участков местности и транспортных средств: некоторые проблемы правового регулирования и проведения / Д. Г. Шашин, А. В. Коршунов // Оперативник (сыщик). - 2016. - № 2 (47). - С. 25-29.

17. Шумилов, А. Ю. О назревшей в теории проблеме разделения прежней оперативно-розыскной и современной оперативно-разыскной деятельности: взгляд сысколога / А. Ю. Шумилов // Оперативник (сыщик). -2014. - № 1 (38). - C. 8-17.

18. Шумилов, А. Ю. Оперативно-разыскная наука в Российской Федерации : монография. В 3 томах. Том $1 /$ А. Ю. Шумилов. - Москва : ИД Шумиловой И. И., 2013- 455c. - ISBN 978-5-89784-184-4.

19. Шумилов, А. Ю. Почему ныне должна быть буква «а», а не буква «о» в терминах «разыскной» и «оперативно-разыскной» / А. Ю. Шумилов // Оперативник (сыщик). - 2016. - № 3 (48). - С. 29-36.

20. Шумилов, А. Ю. Юридические основы оперативно-розыскных мероприятий : учебное пособие / А. Ю. Шумилов. - Москва : Издатель Шумилова И. И., 1999. - 128 с. - ISBN5-89784-018-0.

\section{REFERENCES}

1. Atmazhitov V.M., Bobrov V.G. O zakonodatel'nom regulirovanii operativno-rozysknoideyatel'nosti: nauchnyi doklad [On the legislative regulation of intelligence-gathering activities: a scientific report]. Moscow: ID Shumilova I.I., 2003. $23 \mathrm{p}$.

2. Atmazhitov V.M. On the nature and legal basis of intelligence-gathering activities: a scientific report. In: Konstitutsionnopravovyeproblemyoperativno-rozysknoideyatel'nosti: sbornik materialov Vserossiiskogo kruglogo stola (3 noyabrya 2011 g.) [Constitutional and legal problems of intelligence-gathering activities: proceedings of the all-Russian round table (November 3, 2011)]. Compiled by K.B. Kalinovskii. Moscow: Petropolis, 2012. Pp. 69-86. (In Russ.).

3. Bobrov V.G. On some issues of legislative regulation of intelligence-gathering activities. Politseiskoe pravo=Police Law, 2005, no. 2, pp. 75-83. (In Russ.).

4. Goryainov K.K. Some directions of development of intelligence-gathering activities in the penal system. Operativnik (syshchik)=Field Investigator (Detective), 2006, no. 1 (6), pp. 17-20. (In Russ.).

5. Znikin V. K. Public intelligence-gathering measure cannot be an investigative action. Vestnik Kuzbasskogo instituta=Bulletin of the Kuzbass Institute, 2019, no. 4 (41), pp. 142-146. (In Russ.).

6. Kvasha Yu.F., Vasil'ev N.N. Osnovnye napravleniya (kontseptsiya) operativno-rozysknoi deyatel'nosti operativnykh podrazdelenii organov i uchrezhdenii, ispolnyayushchikh ugolovnye nakazaniya: uchebno-metodicheskie materialy po kursu "Organizatsiya i taktika ORD organov, ispolnyayushchikh nakazaniya" [The main directions (concept) of intelligencegathering activities of operational divisions of bodies and institutions executing criminal punishments: educational and methodological materials for the course "Organization and tactics of IGAs of bodies executing punishments]. Moscow: Akademiya MVD Rossii, 1994. Pp. 22-23.

7. Lugovik V.F. The intelligence-gathering code of the Russian Federation (the author's draft of a federal law). Yuridicheskaya nauka i pravookhranitel'naya praktika=Legal Science and Law Enforcement Practice, 2015, no. 1 (31), pp. 109-135. Available at: https://cyberleninka.ru/article/n/operativno-razysknoy-kodeks-rossiyskoy-federatsii-avtorskiy-proektfederalnogo-zakona/viewer (accessed January 6, 2021).

8. On intelligence-gathering activities: the law of the Republic of Belarus. Official website of "Etalon"- National Center for Legal Information of the Republic of Belarus. Available at: https://etalonline.by/document/?regnum=H11500307 (accessed January 24, 2021). (In Russ.).

9. On intelligence-gathering activities: the law of the Republic of Kazakhstan no. 154-XIII dated September 15, 1994. Information and legal system of normative legal acts of the Republic of Kazakhstan: official website. Available at: http:// adilet.zan.kz/rus/docs/Z940004000_/links (accessed January 24, 2021). (In Russ.).

10. Oganesyan S.S. What spelling is correct: "разыскной"оr "розыскной"? In: Tkachenko E.S. (Ed.). Aktual'nye voprosysovershenstvovaniya rossiiskogo zakonodatel'stva i deyatel'nosti ugolovno-ispolnitel'noi sistemy: sbornik nauchnykh trudov [Topical issues of improving Russian legislation and the activities of the penal system: collection of scientific papers]. Vladimir: Vul FSIN Rossii, 2019. P. 286-291. (In Russ.).

11. Decision of the Constitutional Court of the Russian Federation of October 2, 2003 no. 345-O "On refusal to accept for consideration the request of the Soviet District Court of the city of Lipetsk to verify the constitutionality of Part 4 of Article 32 of the Federal Law of February 16, 1995 "On Communication". In: Operativno-rozysknye meropriyatiya: osnovaniya i usloviya ikh provedeniya: sbornik reshenii Evropeiskogo Suda po pravam cheloveka, Konstitutsionnogo i VerkhovnogoSudov Rossiiskoi Federatsii [Intelligence-gathering activities: grounds and conditions for their implementation: collection of decisions of the European Court of Human Rights, the Constitutional and Supreme Courts of the Russian Federation]. Compiled by K.K. Goryainov, L.E. Shchetnev. Vladimir: Wul FSIN Rossii, 2017. Pp. 48-50. 
12. Nikolyuk V.V. et al. Federal'nyi zakon "Ob operativno-rozysknoi deyatel'nosti”: nauchno-prakticheskii kommentarii [Federal law "On intelligence-gathering activities": scientific and practical commentary]. Omsk: Omsk iiyuridicheskii institut MVD Rossii, 1999. 179 p.

13. Chechetin A.E. Aktual'nye problem y teorii operativno-rozysknykh meropriyatii: monografiya [Actual problems of the theory of intelligence-gatheringmeasures: monograph]. Moscow: ID Shumilovoi I. I., 2006. 180 p.

14. Chechetin A.E. Modern intelligence-gatheringactivities and coercion. Operativnik (syshchik)=Field Investigator (Detective), 2015, no. 1 (42), pp. 37-42. (In Russ.).

15. Shatokhin I.D., Chechetin A.E. Printsip uvazheniya i soblyudeniya prav $i$ svobod cheloveka i grazhdanina v operativnorozysknoideyatel'nosti: monografiya [The principle of respect and observance of human and civil rights and freedoms in intelligence-gatheringactivities: monograph]. Barnaul: Barnaul'skii yuridicheskii institut MVD Rossii, 2020. 206 p.

16. Shashin D.G., Korshunov A.V. Public investigation of premises, buildings, structures, terrain areas and vehicles: some problems of legal regulation and conduct. Operativnik (syshchik)=Field Investigator (Detective), 2016, no. 2 (47), pp. 2529. (In Russ.).

17. Shumilov A.Yu. On the problem of separation of the former intelligence-gathering activities and modern intelligencegathering activities: the view of a detective. Operativnik (syshchik)=Field Investigator (Detective), 2014, no. 1 (38), pp. 8-17. (In Russ.).

18. Shumilov A.Yu. Operativno-razysknaya nauka v Rossiiskoi Federatsii: monografiya [Intelligence-gathering science in the Russian Federation: monograph]. In 3 volumes. Volume 1. Moscow: ID Shumilovoi I. I., 2013. 455 p.

19. Shumilov A.Yu. Why now there should be the letter "a", and not the letter "o"in the terms "разыскной" and "оперативноразыскной". Operativnik (syshchik)=Field Investigator (Detective), 2016, no. 3 (48), pp. 29-36. (In Russ.).

20. Shumilov A.Yu. Yuridicheskie osnovy operativno-rozysknykh meropriyatii: uchebnoe posobie [Legal bases of intelligence-gathering measures: a textbook]. Moscow: Izdatel' Shumilova I. I., 1999. 128 p.

\section{СВЕДЕНИЯ ОБ АВТОРЕ / INFORMATION ABOUT THE AUTHOR}

АЛЕКСЕЙ ВЯЧЕСЛАВОВИЧ АГАРКОВ - КандИДат ЮрИдических наук, доцент, начальник кафедры оперативно-розыскной деятельности юридического факультета Владимирского юридического института ФСИН России, г. Владимир, Российская Федерация. ORCID: https:// orcid.org/0000-0001-5326-9757, e-mail: oper72.kum@ mail.ru
ALEKSEI V. AGARKOV - Candidate of Sciences (Law), Associate Professor, head of the Department of Intelligence-Gathering Activities of the Faculty of Law, Vladimir Law Institute of the Federal Penitentiary Service of Russia, Vladimir, Russian Federation. ORCID: https://orcid. org/0000-0001-5326-9757, e-mail: oper72.kum@mail.ru 